\title{
TEACHERS' TRAINING AND INCLUSIVE METACOGNITIVE TOOLS
}

\author{
Viviana Vinci \\ University of Bari Aldo Moro, Italy
}

\begin{abstract}
A Research\&Training project has been set up involving people attending courses for teaching qualification; the aim was to develop metacognitive tools to create inclusive reflection methodologies aimed at enhancing mental skills dealing with inclusive education. The theoretical framework combines the studies in professional Education and Teachers' Thinking with reflection-based and metacognitive training paradigms. By means of workshops, a reflecive-oriented metacognitive tool for inclusive training has been created; four individual writing activities were carried out, including professional writing, maps and case studies, together with a group project. The results showed the need to develop new educational devices and a shared language of teachers' professional knowledge that can be useful to adapt any context in the inclusive perspective of the so-called Education for all.

Keywords: inclusion; metacognition; training; teachers' professional knowledge; reflection methodologies; Education for all; professional writing, maps; case studies.
\end{abstract}

\section{Introduction}

Inclusive school is designed and structured in order to overcome any education-related barrier and to support an all-inclusive participation (intentionally and a priori) (Booth, Ainscow 2002; Florian 2012; Perla, 2013). It requires training methods that support teachers in the redevelopment of educational contexts, so that they could be aware of their way of thinking in order to implement inclusive practices, thus dispelling some misconceptions that prevent classrooms to be an inclusive setting. This study shows the results of a Research\&Training project that has involved 300 educators in the making (attending courses for teaching qualifications, internships and courses for Special Needs at University of Bari Aldo Moro, Italy, academic years 2013-14 and 2014-15). The final aim was the creation of metacognitive devices (projects, maps, reflective writing activities) to develop inclusive thinking in order to support the metacognitive enhancement of mental skills focused on inclusive education. The theoretical framework refers to professional Education (Lenoir, Vanhulle 2006) and studies known as Teachers' Thinking (Shulman 1986), focused on pre-reflective concepts and educational implicit knowledge of teachers in the making (Perla 2010). 
The aim of the article is to understand what kind of competence and awareness teachers should acquire to make his/her classroom an inclusive setting, what kind of beliefs and representations may influence classrooms' management and the devices that can be used to carry out inclusive training procedures. In 2013 a Research\&Training project was carried out has involved 300 educators attending courses for teaching qualifications and courses for Special Needs at University of Bari Aldo Moro, Italy, in the academic years 2013/14 and 2014/15. The Research\&Training project was developed in four workshops aiming at creating metacognitive devices to develop inclusive thinking and supporting self-reflective implicit, motivational, ideological, cultural and experiential features that are the core of teaching, representing both a resource or a barrier in the development of inclusive practices and cultures. The reflective metacognitive device was developed using four different writing sessions (individual sessions) and a final group project. The papers (projects and individual writings) have been read and analysed by means of quality-based data analysis using NVivo software. Results from this research showed the complexity to put inclusion into practice and to think of its fundamental variables: the educational differentiation achieved by means of a different management of space, the decentralisation of teachers' desks, a different arrangement of students' desks in order to involve the whole class, the central role of workshops and differentiated educational mediators (pictures, drawings, diagrams, concept maps and all devices based on different communication codes), the active role and the participation of all stakeholders in educational actions, the enhancement of environmental, aesthetic and moral education, the central role of manual work, and the evolving role of learning support teachers.

\section{Beyond special Education: the perspective of Education for all}

Inclusion, based on the Education for all perspective, or the need/right to provide education to all those who may be socially excluded (UNESCO, 1994), is a crucial challenge in the most recent European education policies. This is a broad perspective that does not involve only disability (Special education) but anyone who may be socially excluded (women, old people, unemployed, illiterate minors) (Perla 2013). The underlain theoretical framework deals with the social model of disability, developed in Great Britain by M. Oliver and L. Barton and opposite to the bio-medical model based on disablement in biological terms. This perspective, in which human rights, individual differences, anti-discrimination and the enhancement of education quality have to be recognised, entails the identification and the overcoming of environmental and cultural barriers as well as a global involvement; therefore, it focuses on 
people rather than contexts. „Education for all” can be fostered only if educational systems are reorganised, differences are valorised, barriers that hamper participation are cut down, thus providing an answer to the rights and needs of everyone. Inclusive school considers some fundamental aims, not only the override of learning and participation barriers:

- $\quad$ reducing and avoiding any possible disadvantage;

- $\quad$ promoting diversity as a quality;

- $\quad$ using didactic programming with a ,global” approach on the basis of responsibility, community and hospitality;

- $\quad$ promoting collaborative and shared working methods and relations;

- $\quad$ investing on quality human relations, on environment modelling, on strategic, methodological and content-based choices (Perla 2013).

Modelling learning environments inclusively means overcoming the perspective of a simple integration of people with disability or Special Educational Needs (Thomas, Loxley 2007), in favour of a new organisation of social contexts and educational settings, the remodelling of didactic programming and the override of education-related barriers (Booth, Ainscow 2008; Thomas, Loxley 2007; Florian 2012; Perla 2013). It is not a simple „,integration” of students with disability or with Special Educational Needs in conventional contexts, but the development of suitable conditions to enhance individual potentialities, thus overcoming the perspective based on needs and favouring an intentional, a priori intervention. Educators should be able to make sure that school contexts may be fruitful for everybody, enhancing people's participation, reorganising the school framework and organising time, space, educational tools and mediators (Damiano 2013; Perla 2013). The European Agency for Development in Special Needs Education (2011) has also underlined the need of training for educators' competence in the spreading of inclusive practices in all European countries. In order to achieve this cultural change, training methods that support teachers in the redevelopment of educational contexts are required. This entails two perspectives: one deals with the redeveloping of educational contexts and in the understanding of all variables involving school spaces and education mediation (Damiano 2013); on the other hand, they could be aware of their way of thinking in order to implement inclusive practices, thus dispelling some misconceptions that prevent classrooms to be an inclusive setting. Considering this framework, in 2013 a Research\&Training project was carried out in order to understand what kind of competence and awareness teachers should acquire to make his/her classroom an inclusive setting, what kind of beliefs and representations may influence classrooms' management and the devices that can be used to carry out inclusive training procedures. 


\section{Theoretical framework of the Research\&Training project}

The Research\&Training project is part of a theoretical framework that intertwines studies on professional Education (Lenoir, Vanhulle 2006) and Teachers' Thinking (Shulman 1986, 1987) - the development of teachers' professional competence by means of their work and on the impact of prereflective concepts, their beliefs and the educational implicit knowledge of teachers in the making (Perla 2010) - with educational and metacognitive reflective paradigms (Altet et al. 1996; Dewey 1965; Striano 2001; Mortari 2007; Perla 2010) that may overcome the meaning of unaware actions, learning from experience and explaining implicit education actions (Perla 2010). Research on Teachers' Thinking showed the importance of pre-reflective knowledge that is embedded into the apprenticeship period of educators-to-be (Clark, Peterson 1986; Calderhead 1987; Day, Popoe, Denicolo 2013) that is all those elements that typify educators: beliefs, implicit theories, intentions, desires, feelings, memories. These elements, though not made explicit, play a decisive role in the creation of relationships, decisions, rules and management of class activities (Reber 1993; Goodman 1988; Stadler, Frensch 1998; Nespor 1987; Olson, Osborne 1991; Calderhead, Robson 1991; Cabaroglu, Roberts 2000). This is what L. Perla (2010) defined as „implicit” in Education. In particular, some metacognition studies have been reinterpreted (Cross \& Paris 1988; Flavell 1979; Paris, Winograd 1990; Schraw, Moshman 1995; Schraw et al. 2006), that is ,thinking about thinking" methods focused on students, since metacognition was used in this research as a training device of teachers' inclusive thinking. Considering this research framework, this study aimed at understanding and enhancing the point of view of educators in the making about education methodologies, inclusion and competence needed in order to manage students, acknowledging implicit and pre-reflective knowledge of educators in the making as professional knowledge.

\section{Methodology}

The Research\&Training project has involved 300 educators attending courses for teaching qualifications and courses for Special Needs at University of Bari Aldo Moro, Italy, in the academic years 2013/14 and 2014/15.

It was developed aiming at:

creating metacognitive devices to develop inclusive thinking in order to support the metacognitive enhancement of mental skills focused on inclusive education.

- $\quad$ supporting self-reflective implicit, emotive, motivational, ideological, cultural and experiential features that are the core of teaching, 
representing both a resource or a barrier in the development of inclusive practices and cultures;

- $\quad$ supporting a reflective, metacognitive and self-evaluative attitude that teachers in the making may use to be aware of their role (tutoring, supporting, managing educational and mediation strategies);

- supporting the awareness of issues and risks that are part of the teacher's role, which are implicit in any assistance and education relationships (assistance, victimism, a redeeming role towards those in need).

The Research\&Training project was developed in four workshops. The first step dealt with the theoretical framework and the project's aims; then, the reflective/metacognitive device (personal writing sessions and a group project) was described. Working groups were created and writing sessions were carried out; lastly, the participants explained their writings and a final plenary session aimed at discussing and sharing different metacognitive issues.

The reflective metacognitive device was developed using four different writing sessions (individual sessions) and a final group project (three participants in each group).

The individual writing sessions were the following:

- describe a person you consider a model, an example of educational care and try to explain why you consider him/her like this: describe his/her gestures, modes, actions, words, traits that make him/her your „Madame Guerin" (chosen as the most representative example of educational care: she was Victor of Aveyron's housekeeper);

- describe your relationship with problems or obstacles;

- describe your relationship with the idea of diversity;

- describe the features that define teachers' professionalism: together with their actions, try to describe how these actions are carried out (unlike other professionals in domains such as psychology, sociology, medicine, etc.). What are the distinctive features of your profession?;

- Using a mind map, try to represent the idea of ,inclusion”;

The group writing task was the following: „Try to outline an inclusive educational project in its essential features".

Here are some examples of reflective and metacognitive questions:

- Considering the project you have outlined, what issues did you encounter in conceiving an inclusive-oriented project? What was it needed for? What are the core features in conceiving (and developing) an inclusive project?

- Considering the plenary session, are there any recurrent features in your representations? What are the elements that created the most 
marked disagreement? Have you changed your mind after discussing with your colleagues?

- Is there any new question/issue arisen after using this device? Have these reflection activities caused any emotions, feelings, behaviours? What beliefs, thoughts and assumptions may create a barrier to the implementation of an inclusive setting?

- What kind of change does inclusion require?

The papers (projects and individual writings) have been read and analysed by means of quality-based data analysis (Richards, Morse 2009; Perla 2010; 2011; Mortari 2007) using NVivo software (Lewins, Silver 2007; Pacifico, Coppola 2010). The quality-based analysis of text corpora was carried out by identifying categories or conceptual cores, or grouped research materials that represented the main categories drawn from text analyses. The aim of this quality-based analysis was the development of flexible, data-driven local theories. Data coding (open approach) was carried out by conceptualising data; the corpus of texts has been transcribed in „text units”, that is short text strings that could allow the labelling of analysed information. Data was then classified according to its level of abstraction and generalisation, thus making data retrieval easier according to the label to be analysed. The language analysis was carried out using the feature Queries in NVivo software (Word Frequency and Text Search Queries); using some specific selection criteria, any query shows textual data by means of diagrams or tables. Here, only some of the results will be analysed (overall results will be published in a forthcoming volume).

\section{Conclusion}

Results from this research showed the complexity to put inclusion into practice and to think of its fundamental variables.

The main issue deals with its sustainability; an inclusive school system and effective methods to manage classes are possible, but it is really difficult to consider inclusion in didactic school programming. Managing schools and classes as inclusive settings and contexts requires more time and resources to be invested, as well as it implies a cultural, structural, organisational and political change. Considering this need, a common feeling is to be powerless towards this kind of change, and many people feel distant from teachers' actions. The most practical complexity deals with the development of inclusive settings in small and overcrowded classrooms; what is more, temporary teachers do not guarantee continuity of action.

Another element deals with the development of inclusion in secondary schools: inclusive projects are mostly based on workshop activities (theatre, art, environment, music) carried out in extracurricular hours and conceived 
especially in other levels of education. Inclusive education is more likely to be associated with earliest school levels (pre-schools, primary schools), therefore it is more difficult to be conceived at other levels (University, for instance). An issue to be analysed is the relationship between inclusive education and disciplinary education, even if we think that a proper general Education is also a „special” Education, and vice versa. Conceiving inclusion seems to help to focus on some overlooked dimensions such as the unavoidable presence of interdisciplinarity, of sensory education, the participation of family in school life, workshop activities, the development of common good and community, the tight connection between inclusive education and environment, peace, art.

There are some other variables considered as key elements of an inclusive setting: the educational differentiation achieved by means of a different management of space, the decentralisation of teachers' desks (and the resulting teachers' role, now considered an ,invisible director”), a different arrangement of students' desks in order to involve the whole class, the central role of workshops and differentiated educational mediators (pictures, drawings, diagrams, concept maps and all devices based on different communication codes), the active role and the participation of all stakeholders in educational actions (not only teachers but also students, supervisors, families, professionals), the enhancement of environmental, aesthetic and moral education, the central role of manual work, and the evolving role of learning support teachers (providing support to the whole class and not to a single student).

Another aspect deals with the importance of mental health by those who have an education-related role, since they continuously experience psychic, frustration events and defence mechanisms. There is the need to shift from a „missionary, redeeming or helpful" approach - an attitude often present in individual writings especially when referring to students with disability or difficulty - to the awareness of one's professional role (and the resulting limits) by enhancing features such as tutoring and educational encouraging. This condition can be developed during one's professional experience, and for some teachers this is still an ongoing process. Results show a shift throughout time from a „missionary” attitude to a different awareness of one's professional role. There is also the need to reflect on one's own profession, cultural and educational models, but mainly on family educational care models, the latter being more effective than teachers' recollections (there is a clear difficulty in describing teachers' professional traits).

The analysis of writings also shows difficulties connected with personal life (family life, or the ability to cope with disease) and professional events (all teachers feel their job-related insecurity, even for more than ten years). The idea of diversity has a more complex representation, as it is associated with many cultural, sexual, religious, identity-related experiences. Working with teachers in 
„de-constructing diversity" - and the resulting daily educational dilemmas becomes a key device in order to understand and identify the causes for isolation, exclusion, non-recognition of the „Other” from oneself (,diversity is in other's eyes"). The Research\&Training project showed the need to develop a new (and shared) lexis of knowledge and of teachers' professional actions, as well as the resources needed to develop inclusive contexts. The device used proved to be a useful training tool for metacognitive development of enhanced mental skills focused on inclusive education and on the awareness of educational differentiation and mediation (Damiano 2013) as the core ideas of inclusion. There is the need to re-evaluate some inclusive experiences in Italy in order to develop a full-fledged inclusive culture. Some examples are represented by M. Montessori's „Casa dei bambini”; M. Orsi's „Senza Zaino” school; R. Malaguzzi's „Reggio Emilia Approach”; „G. Pizzigoni's „Scuola rinnovata”; V. De Lillo's "Globalismo affettivo". All these examples have a common element: as L. Perla suggests, the common educational approach is ,global”, as well as the conception of school itself, with some precise spaces and times. Here, the focus is not on students with problems or disability (this would create discrimination and a borderline situation), but on the educational conditions that make classrooms warm, welcoming environments for everyone, therefore they become a tool to support education with a distinguished approach, aiming at enhancing the potential of every single student (Perla 2013).

\section{References}

European Agency for Development in Special Needs Education (2011). Teacher education for inclusion across europe. Challenges and opportunities. Odense, Denmark: European Agency for Development in Special Needs Education.

Altet, M., Charlier, E., Paquay, L., \& Perrenoud, P. (1996). Former des enseignants professionnels. Quelles stratégies? Quelles compétence? Paris: De Boeck \& Larcier.

Armstrong, F., Armstrong, D., \& Barton, L. (2000). Inclusive Education: Policy, Contexts and Comparative Perspectives. London: David Fulton Publishers.

Barton, L. (1997). Inclusive education: Romantic, subversive or realistic? International Journal of Inclusive Education, 1, 231-242.

Booth, T., \& Ainscow (2002). Index for Inclusion: developing learning and participation in schools. Bristol: CSIE.

Cabaroglu, N., \& Roberts, J. (2000). Developments in student teachers' preexisting beliefs during a one-year P.G.C.E. programme. System, 28(3), 387-402.

Calderhead, J. (1987). Exploring Teachers' Thinking. London: Cassel Education.

Calderhead, J., \& Robson, M. (1991). Images of teaching: Student teachers' early conceptions of classroom practice. Teaching and Teacher Education, 7(1), 1-8.

Clark, C.M., Peterson, P.L. (1986). Teachers' thought processes. In M.C. Wittrock (Ed.), Handbook of research on teaching (3rd ed., 255-296). New York: Macmillan. 
Proceedings of the International Scientific Conference. Volume III, May $27^{\text {th }}-28^{\text {th }}$, 2016. 212-221

Cross, D.R., \& Paris, S.G. (1988). Developmental and instructional analyses of children's metacognition and reading comprehension, Journal of Educational Psychology, 80(2), 131-142.

Damiano, E. (2013). La mediazione didattica. Per una teoria dell'insegnamento. Milano: Franco Angeli.

Day, C., Pope, M., \& Denicolo, P. (1990). Insights Into Teachers' Thinking And Practice. London: Palmer Press.

Dewey, J. (1933). How We Think. A Restatement of the Relation of Reflective Thinking to the Educative Process. Boston: Heath.

Flavell, J.H. (1979). Metacognition and cognitive monitoring: A new area of cognitive developmental inquiry. American Psychologist, 34(10), 906-911.

Florian, L. (2012). Teacher education for inclusion: A research agenda for the future. In C. Forlin (Ed.). Future directions for inclusive teacher education: An international perspective (210-218). London: Routledge.

Goodman, J. (1988). Constructing a Practical Philosophy of Teaching: a Study of Preservice Teachers' Professional Perspectives. Teaching and Teacher Education, 4(2), 121-137;

Lenoir, Y., \& Vanhulle, S., (2006). L'état de la recherche au Québec sur la formation à l'enseignement. Vers de nouvelles perspectives de recherché. Sherbrooke: Éditions du CRP.

Lewins, A., \& Silver, C. (2007). Using Software in Qualitative Research. A Step-by-Step Guide. London: Sage.

Mortari, L. (2007). Cultura della ricerca e pedagogia. Prospettive epistemologiche. Roma: Carocci,.

Nespor, J. (1987). The Role of Beliefs in the Practice of Teaching. Journal of Curriculum Studies, 19(4), 317-328.

Oliver, M. (1990). The Politics of Disablement. London: Macmillan.

Oliver, M., Barnes, C. (1998). Disabled People and Social Policy: From Exclusion to Inclusion. Harlow: Longman.

Olson, M.R., \& Osborne, J.W. (1991). Learning to Teach: The First Year. Teaching and Teacher Education, 7(4), 331-343.

Pacifico, M., \&Coppola, L. (2010). Nvivo: una risorsa metodologica. Procedure per l'analisi dei dati qualitativi. Milano: Franco Angeli.

Paris, S.G., Winograd, P. (1990). Promoting metacognition and motivation of exceptional children. Remedial and Special Education, 11(6), 7-15.

Perla, L. (2010). Didattica dell'implicito. Ciò che l'insegnante non sa. Brescia: La Scuola.

Perla, L. (2013). Per una didattica dell'inclusione: prove di formalizzazione. Lecce: Pensa Multimedia.

Pijl, S.J., Meijer, C.J.W., \& Hegarty, S. (1997). Inclusive Education: A Global Agenda. London Routledge.

Reber, A.S. (1993). Implicit Learning and Tacit Knowledge: an Essay on The Cognitive Unconscious. Oxford: Oxford University Press.

Richards, L., \& Morse, J.M. (2009). Fare ricerca qualitativa. Prima guida (tr. it). Milano: Franco Angeli.

Schraw, G., Crippen, K.J., \& Hartley, K. (2006). Promoting self-regulation in science education: Metacognition as part of a broader perspective on learning. Research in Science Education, 36, 111-139.

Schraw, G., \& Moshman, D. (1995). Metacognitive theories. Educational Psychology Review, 7(4), 351-371. 
Shulman, L.S. (1986). Paradigms and research programs in the study of teaching: a contemporary perspective. In M.C. Wittrock (Ed.). Handbook of research on teaching (3rd ed.). New York: MacMillan.

Shulman, L.S. (1987). Knowledge and Teaching: Foundations of the New Reform, Harvard Educational Review, 57(1), 1-22.

Stadler, M.A., \& Frensch, P.A. (Eds.) (1998). Handbook of implicit learning. London: Sage.

Striano, M. (2001). La razionalità riflessiva nell'agire educativo. Napoli: Liguori.

Thomas, G., \& Loxley, A. (2007). Deconstructing Special Education And Constructing Inclusion. Maidenhead: Open University Press.

UNESCO, The Dakar Framework for Action. Education for All: Meeting our Collective Commitments Adopted by the World Education Forum. Including six regional frameworks for action, Dakar, Senegal, 26-28 April 2000. 